\title{
Development of software for handling ship's pharmacy
}

\author{
Giulio Nittari ${ }^{1}$, Alessandro Peretti ${ }^{1}$, Fabio Sibilio ${ }^{2}$, Nicholas loannidis ${ }^{3}$, Francesco Amenta ${ }^{1,2}$ \\ ${ }^{1}$ Telemedicine and Telepharmacy Centre University of Camerino, Camerino, Italy \\ ${ }^{2}$ Research Department, International Radiomedical Centre (CIRM), Rome, Italy \\ ${ }^{3}$ Shipmedical Ltd, Athens, Greece
}

\section{ABSTRACT}

Background: Ships are required to carry a given amount of medicinal products and medications depending on the flag and the type of vessel. These medicines are stored in the so called ship's "medicine chest" or more properly - a ship pharmacy. Owing to the progress of medical sciences and to the increase in the mean age of seafarers employed on board ships, the number of pharmaceutical products and medical devices required by regulations to be carried on board ships is increasing. This may make handling of the ship's medicine chest a problem primarily on large ships sailing on intercontinental routes due to the difficulty in identifying the correspondence between medicines obtained abroad with those available at the national market. To minimise these problems a tool named Pharmacy Ship (acronym: PARSI) has been developed. Materials and methods: The application PARSI is based on a database containing the information about medicines and medical devices required by different countries regulations. In the first application the system was standardised to comply with the Italian regulations issued on the $1^{\text {st }}$ October, 2015 which entered into force on the 18 January 2016.

Results: Thanks to PARSI it was possible to standardize the inventory procedures, facilitate the work of maritime health authorities and make it easier for the crew, not professional in the field, to handle the 'medicine chest' correctly by automating the procedures for medicines management. As far as we know there are no other similar tools available at the moment. The application of the software, as well as the automation of different activities, currently carried out manually, will help manage (qualitatively and quantitatively) the ship's pharmacy.

Conclusions: The system developed in this study has proved to be an effective tool which serves to guarantee the compliance of the ship pharmacy with regulations of the flag state in terms of medicinal products and medications. Sharing the system with the Telemedical Maritime Assistance Service may result in avoiding mistakes in drug administration. Last but not least the availability of PARSI could help reduce/ avoid problems with maritime health authorities in case any of the required medicinal products are missing.

(Int Marit Health 2016; 67, 2: 72-78)

Key words: pharmacy ships, software, medicine inventory management, pharmaceutical compound, medical device
\end{abstract}

\section{INTRODUCTION}

Pharmacotherapy is a pillar of modern medicine. This is true also in case of diseases or accidents occurring on board of seagoing vessels [1]. Ships are required to carry given amount of medicines and medical devices which may vary depending on the flag and on the type of the vessels [1, 2]. Medicinal and medical equipment stores form the so called "Ship Medicine Chest". The "Ship Medicine Chest" is not really a chest anymore, but the name is still there, although it would be more appropriate today to define it as ship's pharmacy [2, 3]. 
The types of activities performed on board a ship are entirely different from the ones performed on shore. The situation is complicated by the fact that ships become both a workplace and a living environment for an extended period of time, also, cargo ships do not carry qualified medical or paramedic personnel and sailors have a higher risk of accidents which may result in death or a serious injury [4].

This concern is not completely new, because almost all national law systems - even before the European Union regulations required that medical safety standards are applied and a minimum supply of drugs is carried aboard vessels. A large number of national and international regulations (World Health Organisation [WHO], European Union) [5, 6] makes it difficult for ship officers managing the ship's pharmacy to perform their tasks. Medicinal products considered restricted by some countries are not restricted in others. This could create confusion aggravated by the fact that ship's personnel do not usually have enough knowledge of pharmacology/pharmacy regulations to prepare a cabinet for restricted products before they stop in different countries, e.g. Russia or Nigeria. Another problem may occur as a result of a language barrier; if a given medicine expired or has been used, it would be difficult to replace it with a local product, especially if it is labelled in a rare language.

At the international level, ship pharmacies should follow the regulations/recommendations as listed below:

- An "old" recommendation from WHO/International Labour Office/International Maritime Organisation in the second edition of the International Medical Guide for Ships (IMGS) with the list of types and quantities of medicines to be carried [5].

- This list was updated in the $3^{\text {rd }}$ edition of IMGS [7]. The main problem of the more recent recommendation is that it did not mention the minimum quantities of different active principles to be carried out. In spite of the justifications of the rationale of this choice, this omission apparently has caused more problems than advantages. Problems that were nor approached or solved in the so-called "Quantification Addendum: International Medical Guide for Ships $3^{\text {rd }}$ edition" published in September 2010 [7].

Increasingly complex regulations for medical supplies and the maintenance of ship pharmacies as well as the possibility of getting medicinal products in various countries may make difficult to supervise the ship pharmacy especially for ships sailing on intercontinental routes. In general, seafarers may expect support/help from local pharmacies or organizations selling medicinal products. However, the fact that in the majority of cases they limit their intervention to the sale of medicinal products is not enough support.

In view of this in order to help the ship personnel maintain ship pharmacy, the software called Pharma- cy Ships (acronym: PARSI) was developed. PARSI is a system designed to manage and monitor drug types and quantities available on board ships. It reduces the manual management of the inventory allowing for quick identification of the medicines available on stock which results in their faster administration in case of diseases or injuries on board.

\section{MATERIALS AND METHODS}

\section{MICROSOFT WINDOWS ACCESS SOFTWARE}

Pharmacy Ships is a pharmacy management system, which helps improve inventory management (the type and amount of medicinal products available on board). It was created using the Windows Access 2007 software and it consists of two sections: medicines and medical devices. Both of them have a storing section, access database, with detailed information about particular items and a mask to edit the database according to national regulations. The decision to divide the database into two main parts was taken after careful evaluation of the available data. The medicinal products database includes more information compared to the medical devices database; also medicinal products have a shorter expiry date and are more often used than medical devices.

\section{RESULTS}

\section{SOFTWARE HOMEPAGE}

The first page appearing after opening the program is a report showing, if present, medicines that will expire within the next 30 days. Hence, the report notifies the user in advance of the expiry date of medicinal products available on board (Fig. 1).

\section{MEDICINAL PRODUCTS SECTION}

A snapshot of the medicinal products database is shown in Figure 2.

Each line lists one medicinal products and the following information:

- pharmaceutical class;

- ATC code;

- active ingredient's name;

- pharmaceutical form;

- dose;

- minimum quantity required according to the ship's flag requirements;

- quantity on board;

- expiration date;

- note;

- amount available; this section will indicate with a green sign if the amount available is that required by regulations and a red sign if not. 


\section{Expiring Medicines in $\mathbf{3 0}$ days}

\begin{tabular}{ccccc} 
ID & PHARMACEUTICAL CLASS & DRUGS NAME & PHARMACEUTICALFORM & EXPIRATION DATE \\
\hline $\mathbf{2 1}$ & Antihistamine & Salbutamol & Vial & $\mathbf{3 1 / 0 3 / 2 0 1 6}$
\end{tabular}

Figure 1. Medicines expiring within the next 30 days

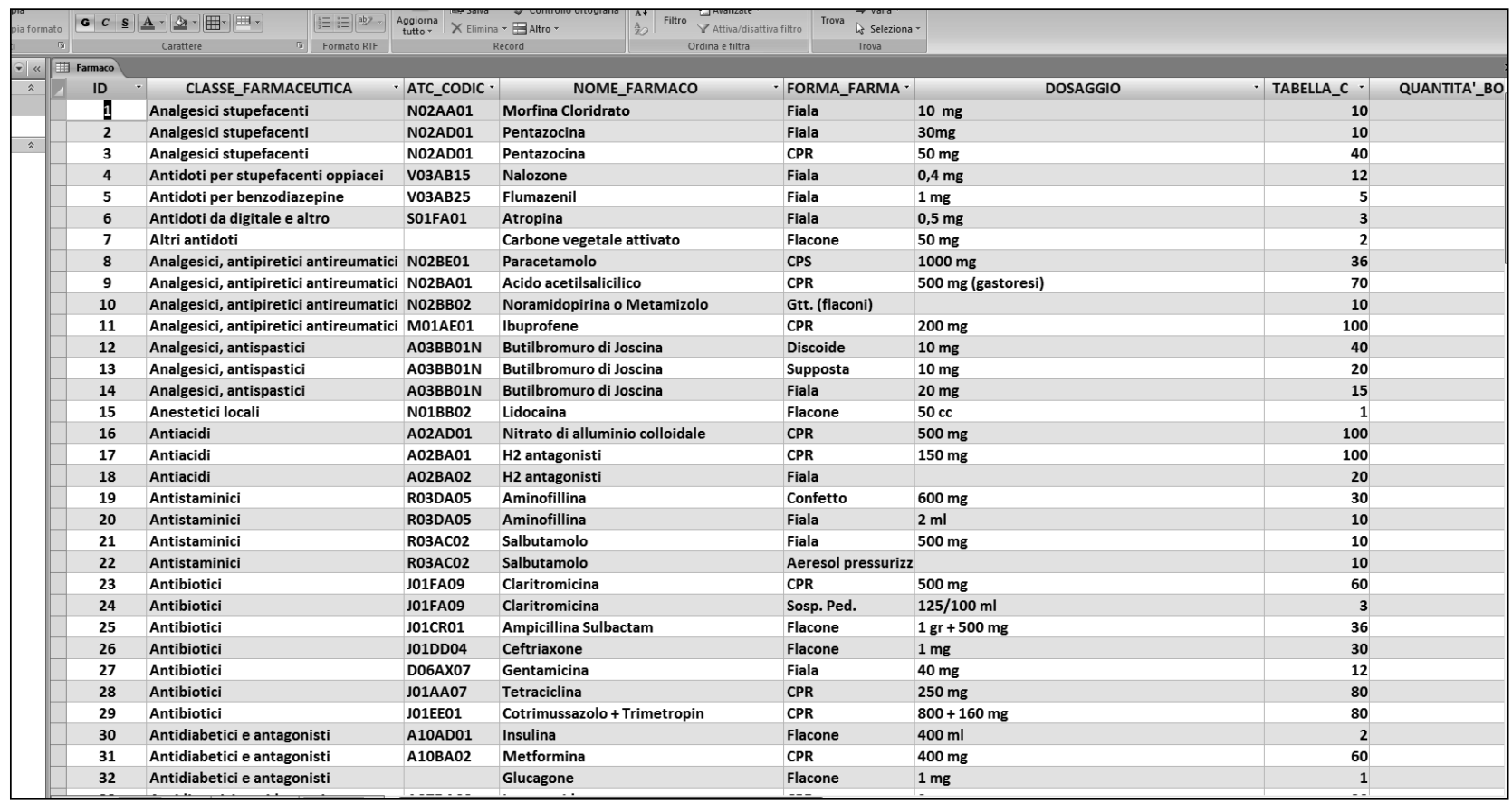

Figure 2. The database containing a list of medicines

The third field appearing in the database is shown in Figure 3. Here, the user can select a specific medicine and instantly obtain the information about the drug chosen. Each user can check the quantity of medicinal products available on board.

The software allows the user to modify some fields such as 'quantity on board'. For instance, if there is an emergency on board and a specific drug is used, an update of the field "quantity on board" must be made/will be stored inside the database. If the amount of a given drug on board is less than required, the software pops up an alert to notify the user that the depot needs to be refilled (Fig. 4).

If the amount of a given medicine on board is less than $50 \%$ of the minimum quantity required, the software pops up another alert. However, in this case, the alert is blocked and the user cannot use the software again before refilling the depot (Fig. 5). There is a field informing the user if the quantity on board is bigger or equal to the minimum quantity required by showing a red " $X$ " or a green "V". In Figure 3 the quantity on board is bigger than the minimum quantity required and thus a green " $V$ " appears on the screen.

The software is capable of monitoring the expiration date of all medicines listed in the database, thus a user can easily see all the medicines expiring within the next 30 days (Fig. 1). The user can print out a copy containing information about the expiry dates of medicinal products at any time. 


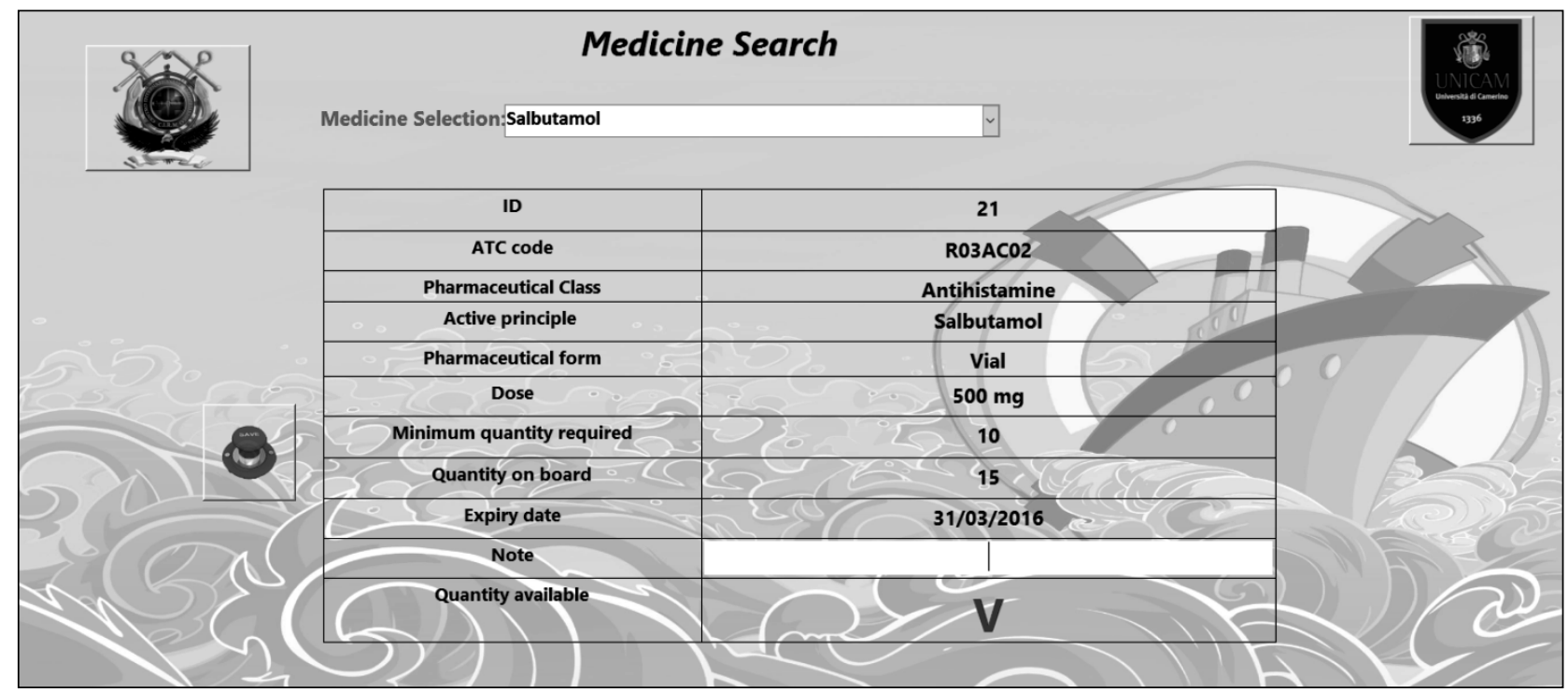

Figure 3. Graphical user interface - a medicine search box

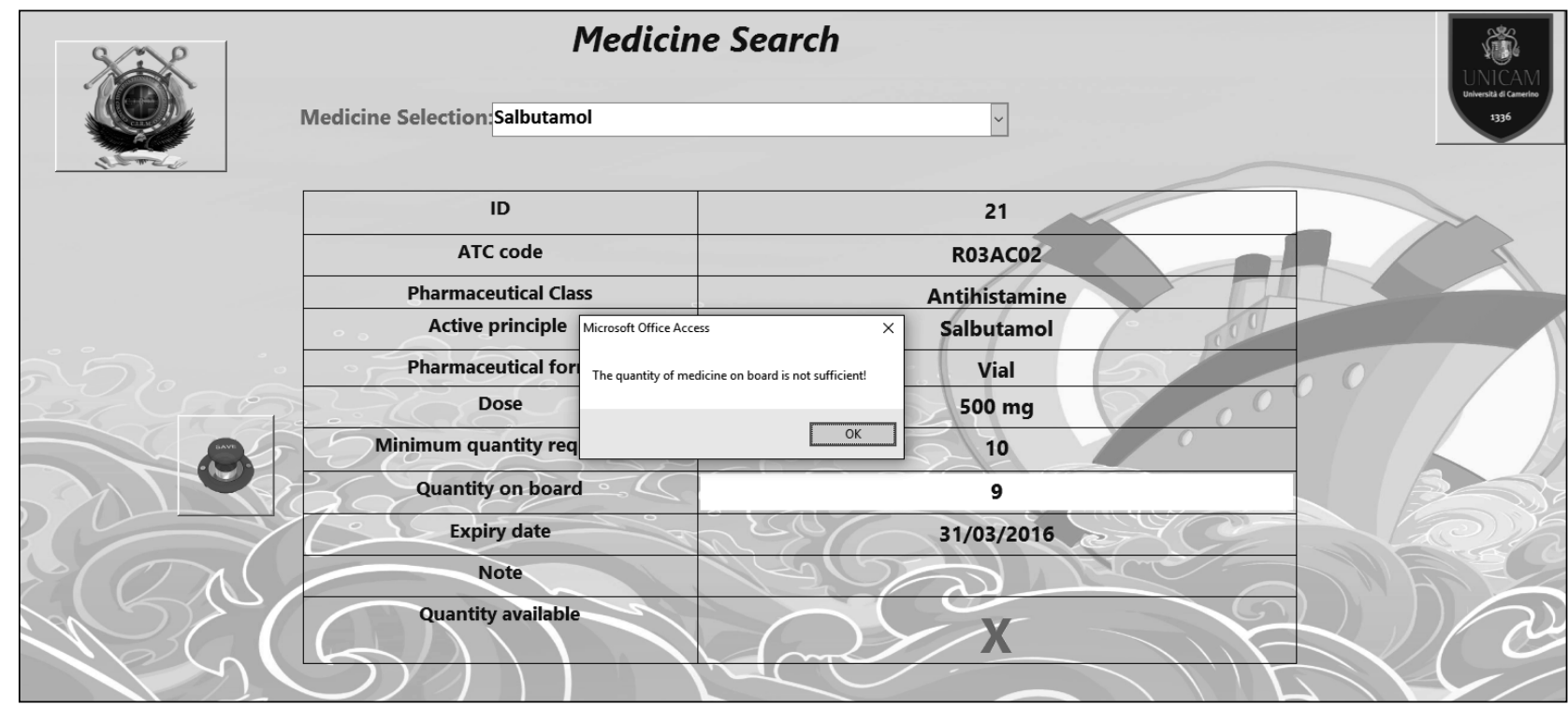

Figure 4. A screenshot of the non-blocking warning created automatically by the software to alert the user that the quantity on board is less than minimum required by regulations

\section{MEDICAL DEVICES SECTION}

The medical devices section is quite similar to the medicinal products section. It includes another database with the information on the medical devices and another mask to manage and modify the related information. For each medical device the following data are included:

- ID;

- group;

- medical device name;

- minimum quantity required;

- quantity on board;

- note;

- amount available (Fig. 6).
The medical device mask has the same functions as the medicinal products section mask. There are two warnings related to the quantity on board when it is less of the minimum quantity required, which has been discussed in the previous section of this article (Fig. 7).

As an additional facility, the software has the ability to create an Excel file with the entire contents of the database for a transfer or printing for monitoring the inventory, thus optimising the timing and the quality of service. PARSI does not require the internet connection which is important as nowadays, most of the ships do not have stable internet connection. In the future, along with technological advance of the telecommunication systems on board, a web software 


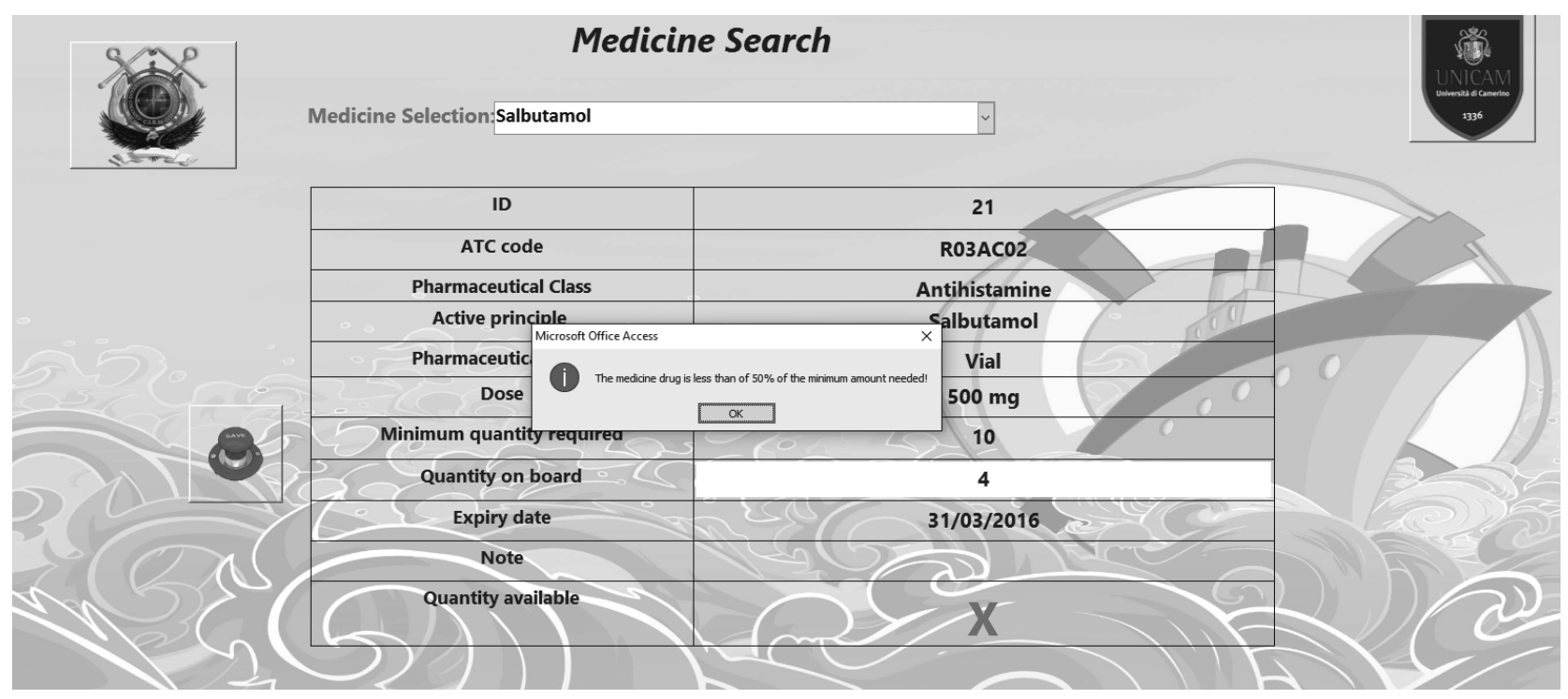

Figure 5. A screenshot of the blocking warning created automatically by the software to alert the user of the quantity on board less than $50 \%$ of the minimum quantity required. An immediate refill is mandatory

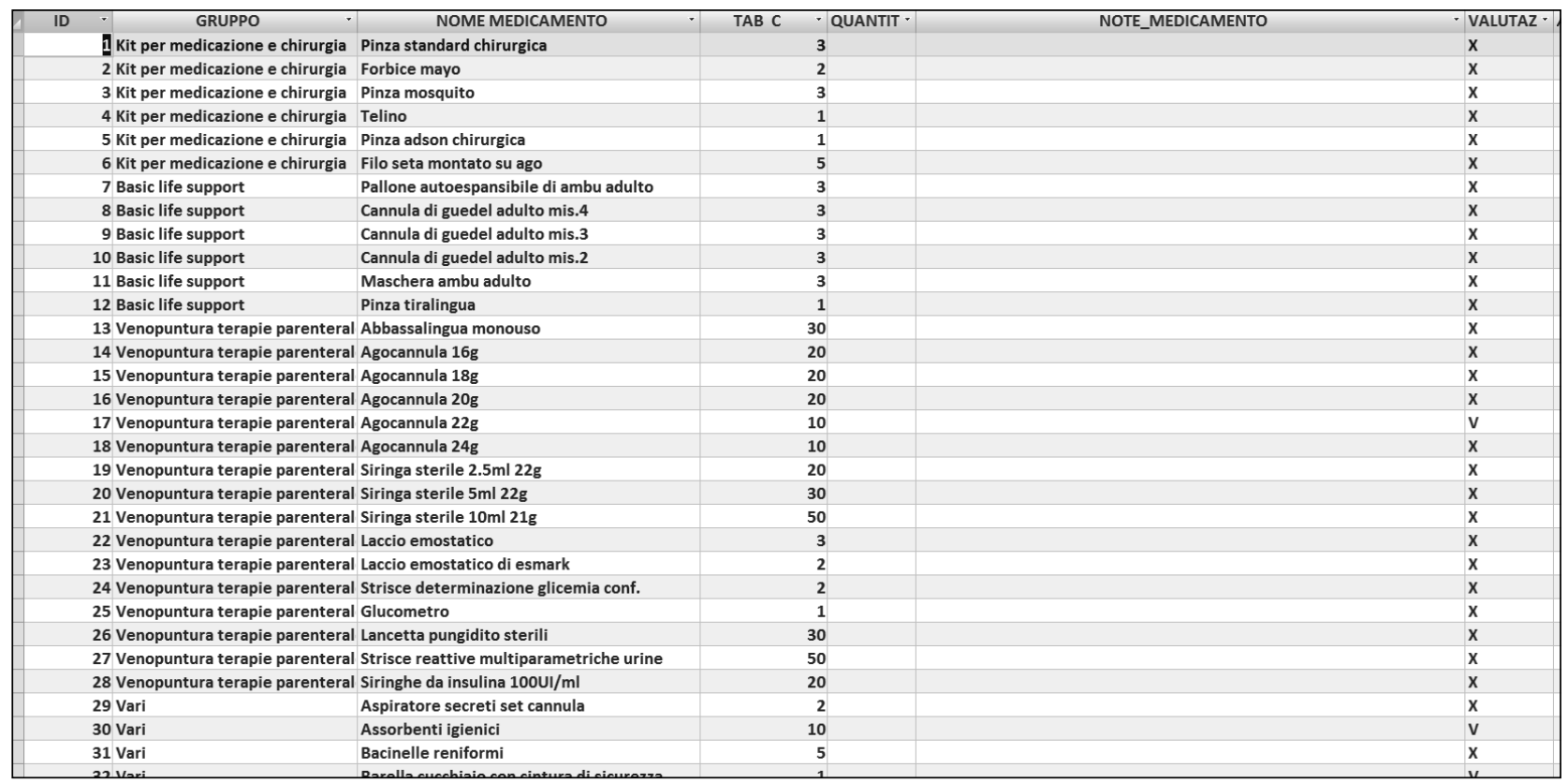

Figure 6. The database containing a list of medical devices

module can be integrated to enable real-time, and independent sea-to-shore communication.

\section{DISCUSSION}

People living ashore usually have an easy access to medical services available. This is not the case with seagoing ships, the majority of which do not have a doctor or any professional medical personnel and may be at sea for days or weeks before they can reach a port. In this situation, the best ways/methods to treat diseases or injuries on board are:
- to provide medical advice via telecommunications systems;

- to guarantee proper training of personnel responsible for health care on board;

- to have an adequate supply of drugs and essential medical equipment (the so called 'ship's medical chest'). The types and quantity of medicinal products and medical devices which need to be stored on board vary greatly depending on the type of ship and the routes the ship follows; the lists of the recommended medicinal products are estab- 


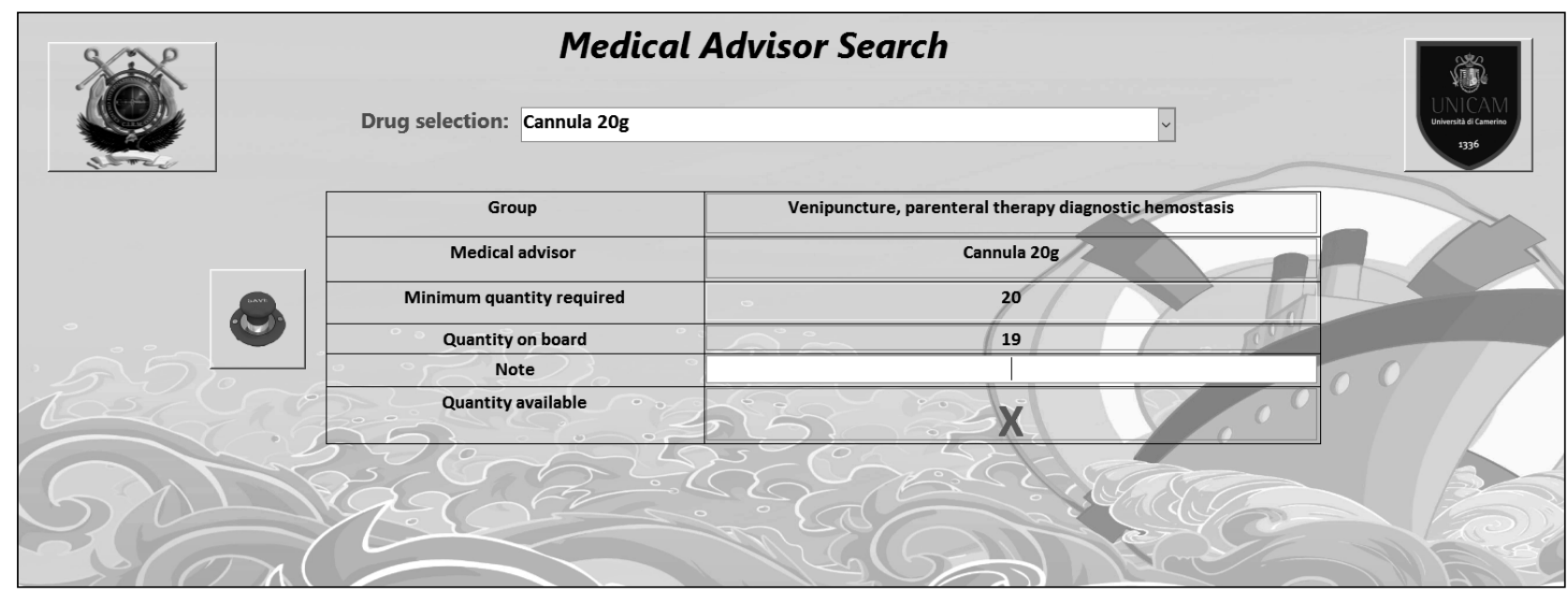

Figure 7. The user interface to handle a medical advisor with a search box

lished by the flag state. International institutions such as the WHO [7] or the European Commission [8] issued specific recommendations on the contents of the ship's medical chest. The WHO guidelines published in 1988 were binding for those states which did not possess their own regulations $[7,8]$.

The old regulations required the captain to check the medical equipment before departure and gave the maritime health authorities the task to deliver/issue the conformity certificate [9]. The presence of a pharmacist on board ships is not required by law [10]. The World Association of Pharmacists (Federation Internationale Pharmaceutique) at their World Congress of 2003 [11] approved a statement on the policy to be pursued by the category on the issue of supply of drugs to the ships and their proper use [11]. The regulations on the contents of the ship's pharmacy issued by the Italian authorities (Decree 1 October 2015) are the newest of those published by other maritime countries [12]. The main novelty consists in the indication of the ATC code [13] for identifying medicinal products and in the possibility to substitute a medicine with an active principle with a similar one with the same therapeutic activity. This principle represents a real innovation in the field and an opportunity to avoid overlap that from time to time can be seen. This makes possible to limit the contents of the ship's medical chest. A problem which still need to be solved is who can establish the therapeutic equivalence taking into account that inspectors delegated to supervise a ship's pharmacy may not have enough knowledge of pharmacology to fulfil this task. A wider use of the ATC codes on board ships may help establish the therapeutic equivalence between cognate substances. In view of the therapeutic affinity of molecules, varying in the ATC code only in the last $2 / 3$ letters/figures, changes of the ATC code within these limits will certainly result in a simpler identification of therapeutic equivalence among molecules of a given class [13]. Of course, the only professionals who can perform the task are pharmacists; therefore they should be given a more defined role in controlling, even remotely, the contents of a ship's pharmacy.

\section{CONCLUSIONS}

To provide support to the ship personnel responsible for handling/managing the ship's pharmacy we have developed the PARSI programme. The purpose of this was to provide standard operative procedures for handling the ship's pharmacy and to automatize some actions which are still carried out manually. PARSI is easy to use, and it allows the user to manage the inventory of drugs and medicaments on board in a mostly automated way possible, thus reducing the risk for potential errors and oversights. Thanks to this computerised system, periodic monitoring of ship's pharmacy is simpler and less time-consuming. The user can search for a specific drug by typing in its active ingredient and/or its ATC code to find out all the information.

In the future, an improved and more attentive handling of the ship's pharmacy will facilitate the management of diseases and accidents occurring on board. Occasionally it is impossible to fill prescriptions issued by the Telemedical Maritime Assistance Service [13] due to the lack of a given drug on board. Monthly reports on the contents of the ship's pharmacy will help avoid these problems. On the other hand, an easier way of classifying medicinal compounds available on board, identified by numbers could be accompanied to the reduction of possible mistakes in administering pharmaceutical compounds to seafarers. To sum up, PARSI offers a unique opportunity to simplify the management of the ship's pharmacy and consequently, to improve the quality of medical assistance on board ships. 


\section{REFERENCES}

1. Goethe WHG, Watson EN, Jones DT (eds.). Goethe Handbook of Nautical Medicine. Springer-Verlag Berlin, Heidelberg 1984.

2. The ship's medicine chest and medical aid at sea. U.S. Department of Health and Human Services Public Health Service Office of the Surgeon General, Rockville 2003.

3. Horneland AM. Ship Medicine Chest - international guidance. Norwegian Centre for Maritime Medicine 2008.

4. Schlaich C, Reinke A, Sevenich C et al. Interim advice regarding the best use of the medical chest for ocean-going merchant vessels without a doctor onboard. Int Marit Health 2009; 60: 1-2.

5. Amenta F, Dauri A, Rizzo N. Telemedicine and medical care to ships without a doctor on board. Journal Telemedicine Telecare 1998; 4 (suppl. 1): 445.

6. The Ship's Medicine Chest and Medical Aid at Sea Paperback. US Public Health Service, December 2001.
7. World Health Organization. International Medical Guide for Ships. WHO, Geneva 2007.

8. World Health Organization. Quantification Addendum: International Medical Guide for Ships. WHO, Geneva 2010.

9. Gazzetta Ufficiale n. 140 del 19-06-2001. Available at: http://gazzette.comune.jesi.an.it/ 2001/140/2.htm. Accessed: 20/04/2016.

10. Dir. CEE 31 marzo 1992 n. 92/29. Prescrizioni minime di sicurezza e di salute per promuovere una migliore assistenza medica a bordo delle navi. Capitolo 20, 1045-1066.

11. Modificazioni della Tabella allegato al decreto 25 Maggio $1988 \mathrm{n}$. 279. Ministero della Salute, Gazzetta Ufficiale Repubblica Italiana, 18/11/2015, Serie Generale-n.269.

12. Norwegian Institute of Public Health. Structure and Principle. International language for drug utilization research, Norway 2011.

13. International Maritime Organization. Medical Assistance at Sea. London, 20 June 2000. 